\title{
The efficacy and acceptability of psychological interventions for depression: where we are now and where we are going
}

\begin{abstract}
Steven. D. Hollon*
Department of Psychology, Vanderbilt University, 306 Wilson Hall, Nashville, TN 37240, USA

Depression is an eminently treatable disorder, although estimates of treatment efficacy have been inflated by publication bias. Patients with less severe depressions respond to even nonspecific interventions, whereas patients with more severe depressions require treatments that mobilize specific mechanisms. The cognitive and behavior therapies can be as efficacious as medications in the treatment of severe depression and have an enduring effect that medications lack. Medications may interfere with those enduring effects when added in combination and may prolong the life of the underlying episode when used alone. Thus the cognitive behavioral interventions might be the optimal first-line treatments for depression.
\end{abstract}

First published online 27 August 2015

Key words: Depression, precision medicine, prevention, treatment.

\section{Is treatment as efficacious as is currently believed?}

Several different types of interventions have been established in the treatment of major depressive disorder (MDD), but the efficacy of those interventions has been overestimated in the published literature. This appears to be true with respect to both the antidepressant medications (ADMs) and psychotherapy. Turner et al. (2008) found that only half the studies submitted to the Food and Drug Administration to secure marketing approval found active medication to be superior to pill-placebo and that over $90 \%$ of those positive studies ended up being published $v$. only about a third of those with null findings. Moreover, nearly all of the 'failed' studies that did get published were 'spun' to make it appear that ADM was superior to pill-placebo. Correcting for publication bias reduced the estimated effect of medication by about a third. Cuijpers et al. (2010) found comparable magnitude of publication bias in the psychotherapy literature, although this had to be inferred from a relative deficit of small studies with weak effects. What this means is that someone reading the published literature would come away thinking that both ADM and psychotherapy are more efficacious than they really are. It is not that they do not work; just that they do not work as well as the published literature would lead one to believe.

\footnotetext{
* Address for correspondence: Steven D. Hollon, Ph.D., Department of Psychology, Vanderbilt University, 306 Wilson Hall, Nashville, TN 37240, USA.

(Email: steven.d.hollon@vanderbilt.edu)
}

Does treatment have a specific effect for less severe patients?

Fournier et al. (2010) plotted treatment outcome as a function of initial severity at the level of the individual patient and found that ADM separated from pillplacebo only among patients with more severe depressions. Patients with less severe depressions (over half of the sample) did about as well on pill-placebo as they did on active medications. This means that they are responding to psychological rather than pharmacological mechanisms. Something similar appears to be the case for the psychosocial interventions. Driessen et al. (2010) found that psychosocial interventions only exceeded non-specific controls among patients with more severe depressions. As for medications, this suggests that non-specific factors account for a large portion of the effects of psychotherapy. Cuijpers et al. (2012) used a meta-analytic approach to decompose the effects of different aspects of change in treatment. What they found was that spontaneous remission accounted for nearly a third of the change observed and non-specific factors nearly half. Specific mechanisms accounted for only about a sixth of the variance in outcomes and likely would have accounted for none if the sample had been restricted to only patients with less severe depressions. For less severe depressions, something works better than nothing and nothing works better than anything else, drug or psychotherapy.

\section{Is specificity required for more severe patients?}

If specific effects are needed at all, they appear to only be needed for patients with more severe (or possibly 
chronic or co-morbid) depressions and then only emerge when those interventions are competently implemented. This can be illustrated by two of the studies included in the reviews just cited with respect to severity (Driessen et al. 2010; Fournier et al. 2010). In the National Institute of Mental Health's (NIMH) Treatment of Depression Collaborative Research Program (TDCRP), both ADM and interpersonal psychotherapy (IPT) were better than pill-placebo among patients with more severe depressions, but did not separate from pill-placebo among patients who were less severe (Elkin et al. 1989). Both ADM and behavioural activation (BA) showed the same pattern in a trial conducted in Seattle; superior to pill-placebo among patients with more severe depressions, but not separating from pill-placebo among patients who were less severe (Dimidjian et al. 2006). Cognitive therapy (CT) was comparable with ADM and both superior to pillplacebo in a study restricted solely to patients with more severe depressions (DeRubeis et al. 2005). The basic point is that specificity is sometimes evident, but only among patients with more severe depressions.

\section{Must interventions be competently implemented to generate a specific effect?}

The further point is that interventions need to be adequately implemented in order to generate a specific effect. CT did not separate from pill-placebo in either the TDCRP or the Seattle study regardless of depression severity and was less efficacious than ADM in both and IPT or BA in each among patients with more severe depressions, but questions can be raised about the adequacy of the implementation of CT in both. Supervision was cutback following initial training for the relatively inexperienced therapists in the TDCRP and site differences were consistent with differences in prior experience with the respective modalities (Jacobson \& Hollon, 1996). In the Seattle trial, only off-site supervision was available (often with a week or more delay) to the somewhat less experienced CT therapists, whereas supervision was available on-site and without delay to the BA therapists, including the lead author on the original manual (Martell et al. 2001). No such concerns have been raised about the adequacy of the CT provided at the University of Pennsylvania site in the study by DeRubeis et al. (2005). That was where CT was first developed and the therapists at that site were particularly competent in its implementation, much as was the case for the BA therapists in the Seattle study. Allegiance effects are known to account for a considerable portion of the variability in direct comparisons across the outcome literature (Luborsky et al. 1999) and it is likely that such allegiance is a marker for competence to implement the respective interventions (Leykin \& DeRubeis, 2009). CT was superior to ADM in the first direct comparison between the two modalities (Rush et al., 1977), but only because doses were low and ADM was discontinued 2 weeks before the end of treatment (Meterissian \& Bradwejn, 1989). The same was likely true when BA was found to be superior to ADM in a trial conducted in Iran; sertraline were capped at $100 \mathrm{mg} /$ day, about half its recommended maximum dose (Moradveisi et al. 2013). Treatment differences are particularly likely to emerge when comparators are less than adequately implemented.

\section{How do we generate treatment guidelines that we can trust?}

Efforts to evaluate the quality of the studies included in quantitative reviews are useful so far as they are, but rarely go beyond features related to the internal validity of the study (Higgins \& Green, 2011). These are all important considerations, but they do little to address issues related to the quality of implementation described in the previous section. The data do not interpret themselves and risks can arise as readily from ignorance as from bias. It has become standard in the field to generate treatment guidelines based on systematic reviews of the empirical literature (often incorporating meta-analyses) that are then processed by multidisciplinary guideline panels comprised of members with diverse perspectives (Institute of Medicine, 2011). This is the process that we are following to generate guidelines for the American Psychological Association (Hollon et al. 2014a). This ensures that key segments of the literature (including the unpublished studies) are not overlooked, but still allows judgement to be brought to bear with respect to the number and quality of studies (including treatment implementation) speaking to a given intervention. Gaps in the literature can be taken into consideration and the diverse perspectives of the panelists ensure that no perspective can bias the review. In essence, guideline panels rely on the principle of adversarial collaboration to protect against the introduction of bias when interpreting the findings of the systematic reviews (Mellers et al. 2001). For example, most meta-analyses of the depression literature suggest that dynamic psychotherapy is as efficacious as IPT (Cuijpers et al. 2008). Nonetheless few depression guidelines give them equal weight (National Institute for Health and Clinical Excellence, 2010). That is because dynamic psychotherapy has been tested in fewer trials and has yet to be shown to be superior to either non-specific controls (Barber et al. 2012) or other types of treatments (Driessen et al. 2013) in clinically representative samples, whereas IPT was found 
to be superior to pill-placebo (and a poorly implemented CT) among patients with more severe depressions in the TDCRP (Elkin et al. 1989). Purely quantitative reviews can only summarise the existing empirical data, whereas guideline panels can make qualitative judgements that put those findings in perspective.

\section{Can psychotherapy be as efficacious as ADM with more severe depressions?}

Several different psychotherapies have been shown to be as efficacious as ADM when adequately implemented. CT was comparable with ADM and each superior to pillplacebo in the reduction of acute distress in two trials, one in a sample of patients with more severe depressions (DeRubeis et al. 2005) and the other in a sample of patients with atypical depressions (Jarrett et al. 1999), whereas ADM was superior to CT of questionable quality with more severe depressions in the two trials noted above (Elkin et al. 1989; Dimidjian et al. 2006). BA was comparable with ADM and each superior to pill-placebo among patients with more severe depressions with no differences among patients with less severe depressions in the Seattle study (Dimidjian et al. 2006). IPT was comparable with ADM and each superior to pill-placebo among patients with more severe depressions but not those who were less severe in the TDCRP (Elkin et al. 1989). The empirically supported psychotherapies appear to be able to do at least as well as ADM when each is adequately implemented. Similarly, ADM has only failed when it has been poorly implemented, whether relative to CT (Rush et al. 1977) or BA (Moradveisi et al. 2013). The jury is still out with respect to dynamic psychotherapy. It did as well as ADM in a recent trial, but neither separated from pill-placebo (Barber et al. 2012) and it did not differ from CT of unknown quality in another trial that lacked a nonspecific control or ADM comparison (Driessen et al. 2013). Null findings can be hard to interpret.

\section{Do CT and BA have enduring effects that protects against relapse?}

CT has an enduring effect that protects patients against subsequent relapse following treatment termination and the same might be true for BA. No such effect has been found for ADM. As good as they are, medications only work for so long as you take them. Cuijpers et al. (2013) found evidence for an enduring effect for prior CT $v$. prior ADM in six of eight comparisons (with non-significant differences favouring prior CT in the seventh). This is a remarkably robust finding. Moreover, prior CT was superior to continuation ADM (the current standard) at the level of a nonsignificant trend. In a separate study, prior BA was superior to prior ADM and did not differ from continuation ADM in the one trial in which it was examined (Dobson et al. 2008). No such evidence exists for any other type of psychotherapy, although only IPT has been tested and then only once (Shea et al. 1992). What this means is that either CT or BA might represent the optimal first-line treatments for most patients since each can hold its own vis-à-vis ADM in the treatment of even more severe depressions (if adequately implemented) and each has an enduring effect not found for ADM (if BA's enduring effect replicates). It would be good to know if other types of psychotherapies also have enduring effects.

\section{Can we select the best treatment for a given patient?}

Main effects for treatments can mask considerable variability in response at the level of the individual patient. In a recent trial, we found that adding CT to ADM enhanced rates of recovery by a modest $10 \%$ across the full sample, but that increment rose to nearly $30 \%$ for the third of the patients who were both more severe and non-chronic (Hollon et al. 2014b). Non-chronic patients who were not severely depressed (another third of the sample) did not need the addition of CT to do well on ADM alone and patients who had chronic depressions regardless of severity (the final third of the sample) did not benefit from its addition. In that trial, a modest main effect masked quite large effects in a subset of the sample. It is likely that similar instances of moderation likely have gone undetected in the literature. We now have the tools not only to detect such instances of moderation, but also to combine them into powerful algorithms that can be used to select the optimal treatment for a given patient. DeRubeis et al. (2014) recently described a personal advantage index (PAI) that uses a 'left one out' jackknife procedure to combine multiple prognostic and prescriptive indices into a single index that optimises treatment choice at the level of the individual patient. Generating PAIs for the patients in the study by DeRubeis et al. (2005), found that a quarter of the sample should have gotten ADM and another quarter of the sample should have gotten CT (the remaining patients showed no differential benefit). Had the optimal treatment had been provided for each patient, it would have improved outcomes by the magnitude of the typical drug-placebo difference. In effect, we could have made treatment more efficient by giving the optimal treatment to each patient without changing at all the nature of either treatment. This is a most exciting prospect.

\section{Does ADM interfere with CT's enduring effect?}

There is one dark cloud on the horizon. In the trial described above, CT was discontinued at the point of 
recovery (for those who received it) and patients were randomised to either maintenance medication or medication withdrawal and followed over the next 3 years to assess for recurrence (onset of new episodes). There was a large effect for maintenance medication (as expected) but little evidence of any enduring effect for prior CT (DeRubeis, personal communication). This was not what we expected and not consistent the enduring effect that we observed for prior CT relative to recovered patients withdrawn from medications following a year of continuation treatment (Hollon et al. 2005; Dobson et al. 2008). This raises the possibility that adding $\mathrm{ADM}$ in combination may interfere with $\mathrm{CT}^{\prime}$ 's enduring effect. There is precedence for this in the panic literature. Barlow et al. (2000) found that providing ADM in combination wiped out the enduring effect observed for prior cognitive behaviour therapy (CBT) relative to ADM alone, whereas patients who received pill-placebo in combination were no more likely to relapse following treatment termination than patients treated with CBT alone. This means that the interference effect was clearly pharmacological in nature and not merely psychological. What is needed is a trial that compares CBT $v$ ADM $v$ combined treatment (preferably with both active ADM and pill-placebo) in terms of rates of relapse following treatment termination in depressed patients.

\section{Does ADM have an iatrogenic effect that prolongs the underlying episode?}

Depression has traditionally been considered to be a self-limiting disorder. That is, most episodes eventually will remit spontaneously even in the absence of treatment (Monroe \& Harkness, 2011). However, depression appears to coarsened in recent years (Whitaker, 2010) and there are concerns that ADMs may suppress symptoms at the expense of prolonging the life of the underlying episode (Forand et al. 2013). ADMs do not so much redress deficits in actual neurotransmitter levels; rather they trigger counterregulatory homeostatic processes that oppose the initial effects of medications (Hyman \& Nestler, 1996). In the process, they perturb the neurotransmitter system, shutting down synthesis in the presynaptic neurons and reducing post-synaptic sensitivity (Andrews et al. 2015) and the greater the perturbation produced by the specific ADM the greater the risk for relapse when withdrawn (Andrews et al. 2011). Whether that affects the same homeostatic mechanisms responsible for spontaneous remission is a matter of conjecture, but the current trend is to keep recurrent patients on lifetime medications. This is what would be expected if ADMs prevented spontaneous remission from taking place. All the evidence suggesting an enduring effect for prior CT is based upon comparisons to medication discontinuation and it is possible that what appears to be an enduring effect for the CBT is in fact an iatrogenic effect for ADM. What is needed is a design in which patients are treated to recovery (sustained remission) with CT or ADM or a pillplacebo control. Treatment would be terminated at the point of recovery and patients followed over the next several years to assess for recurrence. If CT is truly preventive, then it should do better than prior placebo; if ADM is iatrogenic, then it should do worse. Such a design would clarify the nature of the long-term effects of each.

\section{Conclusions}

Both ADM and psychotherapy are efficacious in the treatment of depression although neither works as well as the published literature would suggest and specific effects only appear to emerge among patients with more severe depressions. Several different psychotherapies can be as efficacious as ADM when adequately implemented and CT and possibly BA appear to have enduring effects that protect against subsequent symptom return following treatment termination. Combined treatment enhances response for some patients, but may interfere with $\mathrm{CT}^{\prime}$ 's enduring effect for all and ADMs may suppress symptoms at the expense of prolonging the underlying episode. Thus, CT or BA might be the optimal first-line treatments for the majority of patients.

\section{Acknowledgements}

The author would like to acknowledge his close colleague Robert J. DeRubeis, Ph.D. who contributed to many of the ideas expressed in this editorial.

\section{Financial support}

This editorial received no specific grant from any funding agency, commercial or not-for-profit sectors.

\section{Conflict of Interest}

None

\section{References}

Andrews PW, Kornstein SG, Halberstadt LJ, Gardner CO, Neale MC (2011). Blue again: perturbational effects of antidepressants suggest monoaminergic homeostasis in major depression. Frontiers in Psychology 2, 159.

Andrews PW, Bharwania A, Lee KR, Fox M, Thomson JA Jr (2015). Is serotonin an upper or a downer? The evolution of the serotonergic system and its role in depression and the 
antidepressant response. Neuroscience and Biobehavioral Reviews 51, 164-188.

Barber JP, Barrett MS, Gallop R, Rynn MA, Rickels K (2012). Short-term dynamic psychotherapy versus pharmacotherapy for major depressive disorder: a randomized, placebo controlled trial. Journal of Clinical Psychiatry 73, 66-73.

Barlow DH, Gorman JM, Shear MD, Woods SW (2000). Cognitive-behavioral therapy, imipramine, or their combination for panic disorder: a randomized controlled trial. JAMA 283, 2529-2536.

Cuijpers P, van Stratten A, van Oppen P, Andersson A (2008). Are psychological and pharmacological interventions equally effective in the treatment of adult depressive disorders? A meta-analysis of comparative studies. Journal of Clinical Psychiatry 69, 1675-1685.

Cuijpers P, Smit F, Bohlmeijer E, Hollon SD, Andersson G (2010). Is the efficacy of cognitive behaviour therapy and other psychological treatments for adult depression overestimated? A meta-analytic study of publication bias. British Journal of Psychiatry 196, 173-178.

Cuijpers P, Driessen E, Hollon SD, van Oppen P, Barth J, Andersson G (2012). The efficacy of non-directive supportive therapy for adult depression: a meta-analysis. Clinical Psychology Review 32, 280-291.

Cuijpers P, Hollon SD, van Straten A, Bockting C, Berking M, Andersson G (2013). Does cognitive behavior therapy have an enduring effect that is superior to keeping patients on continuation pharmacotherapy? BMJ Open 3, e002542.

DeRubeis RJ, Hollon SD, Amsterdam JD, Shelton RC, Young PR, Salomon RM, O'Reardon JP, Lovett ML, Gladis MM, Brown LL, Gallop R (2005). Cognitive therapy vs. medications in the treatment of moderate to severe depression. Archives of General Psychiatry 62, 409-416.

DeRubeis RJ, Cohen Z, Forand NR, Fournier JC, Gelfand L, Lorenzo-Luaces L (2014). The personalized advantage index: translating research on prediction into individualized recommendations. A demonstration. PLOS ONE 9, e83875.

Dimidjian S, Hollon SD, Dobson KS, Schmaling KB, Kohlenberg RJ, Addis ME, Gallop R, McGlinchey JB, Markley DK, Gollan JK, Atkins DC, Dunner DL, Jacobson NS (2006). Behavioral activation, cognitive therapy, and antidepressant medication in the acute treatment of major depression. Journal of Consulting and Clinical Psychology 74, 658-670.

Dobson KS, Hollon SD, Dimidjian S, Schmaling KB, Kohlenberg RJ, Gallop RJ, Rizvi SL, Gollan JK, Dunner DL, Jacobson NS (2008). Randomized trial of behavioral activation, cognitive therapy, and antidepressant medication in the prevention of relapse and recurrence in major depression. Journal of Consulting and Clinical Psychology 76, 468-477.

Driessen E, Cuijpers P, Hollon SD, Dekker JJM (2010). Does pretreatment severity moderate the efficacy of psychological treatment of adult outpatient depression? A meta-analysis. Journal of Consulting and Clinical Psychology 78, 668-680.
Driessen E, Van HL, Don FJ, Peen J, Kool S, Westra D, Hendriksen M, Schoevers RA, Cuijpers P, Twisk JWR, Dekker JJM (2013). The efficacy of cognitive-behavioral therapy and psychodynamic therapy in the outpatient treatment of major depression: a randomized clinical trial. American Journal of Psychiatry 170, 1041-1050.

Elkin I, Shea MT, Watkins JT, Imber SD, Sotsky SM, Collins JF, Glass DR, Pilkonis PA, Leber WR, Docherty JP, Fiester SJ, Parloff MB (1989). National Institute of Mental Health Treatment of Depression Collaborative Research program: general effectiveness of treatments. Archives of General Psychiatry 46, 971-982.

Forand NR, DeRubeis RJ, Amsterdam JA (2013). Combining medication and psychotherapy in the treatment of major mental disorders. In Garfield and Bergin's Handbook of Psychotherapy and Behavior Change, 6th edn. (ed. MJ Lambert), pp. 735-774. Wiley: New York.

Fournier JC, DeRubeis RJ, Hollon SD, Dimidjian S, Amsterdam JD, Shelton RC, Fawcett J (2010). Antidepressant drug effects and depression severity: a patient-level meta-analysis. JAMA 303, 47-53.

Higgins JPT, Green S (2011). Cochrane Handbook for Systematic Reviews of Interventions Version 5.1.0 [Updated March 2011]. The Cochrane Collaboration. Available from www.cochrane-handbook.org.

Hollon SD, DeRubeis RJ, Shelton RC, Amsterdam JD, Salomon RM, O'Reardon JP, Lovett ML, Young PR, Haman KL, Freeman BB, Gallop R (2005). Prevention of relapse following cognitive therapy versus medications in moderate to severe depression. Archives of General Psychiatry 62, 417-422.

Hollon SD, Areán PA, Craske MG, Crawford KA, Kivlahan DR, Magnavita JJ, Ollendick TH, Sexton TL, Spring B, Bufka LF, Galper DG, Kurtzman H (2014a). Development of clinical practice guidelines. Annual Review of Clinical Psychology 10, 213-241.

Hollon SD, DeRubeis RJ, Fawcett J, Amsterdam JD, Shelton RC, Zajecka J, Young PR, Gallop R (2014b). Cognitive therapy enhances rate of recovery to antidepressant medications for patients with major depressive disorder: a randomized controlled trial. JAMA Psychiatry 71, 1157-1164.

Hyman SE, Nestler EJ (1996). Initiation and adaptation: a paradigm for understanding psychotropic drug action. American Journal of Psychiatry 153, 151-162.

Institute of Medicine (IOM) (2011). Clinical Practice Guidelines We Can Trust. National Academy Press: Washington, DC.

Jacobson NS, Hollon SD (1996). Prospects for future comparisons between drugs and psychotherapy: lessons from the CBT vs. pharmacotherapy exchange. Journal of Consulting and Clinical Psychology 64, 104-108.

Jarrett RB, Schaffer M, McIntire D, Witt-Browder A, Kraft D, Risser RC (1999). Treatment of atypical depression with cognitive therapy or phenelzine: a double-blind, placebocontrolled trial. Archives of General Psychiatry 56, 431-437.

Leykin Y, DeRubeis RJ (2009). Allegiance in psychotherapy research: separating association from bias. Clinical Psychology: Science and Practice 16, 54-65. 
Luborsky L, Diguer L, Seligman DA, Rosenthal R, Krause ED, Johnson S, Halperin G, Bishop M, Berman JS, Schweizer E (1999). The researcher's own therapy allegiances: a 'wild card' in comparisons of treatment efficacy. Clinical Psychology: Science and Practice 6, 95-106.

Marcus SC, Olfson M (2010). National trends in the treatment of depression from 1998 to 2007. Archives of General Psychiatry 67, 1265-1273.

Martell CR, Addis ME, Jacobson NS (2001). Depression in Context: Strategies for Guided Action. Norton: New York.

Mellers B, Hertwig R, Kahneman D (2001). Do frequency representations eliminate conjunction effects: an exercise in adversarial collaboration. Psychological Science 12, 269-275.

Meterissian GB, Bradwejn J (1989). Comparative studies on the efficacy of psychotherapy, pharmacotherapy, and their combination in depression: was adequate pharmacotherapy provided? Journal of Clinical Psychopharmacology 9, 334-339.

Monroe SM, Harkness KL (2011). Recurrence in major depression: a conceptual analysis. Psychological Review 118, 655-674.

Moradveisi L, Huibers MJH, Renner F, Arasteh M, Arntz A (2013). Behavioural activation v. antidepressant medication for treating depression in Iran: randomised trial. British Journal of Psychiatry 202, 204-211.

National Institute for Health and Clinical Excellence (2010). Depression: The Treatment and Management of Depression in Adults, Updated edn. NICE Clinical Guideline 90. Available from www.nice.org.uk/CG90

Rush AJ, Beck AT, Kovacs M, Hollon SD (1977). Comparative efficacy of cognitive therapy and pharmacotherapy in the treatment of depressed outpatients. Cognitive Therapy and Research 1, 17-37.

Shea MT, Elkin I, Imber SD, Sotsky SM, Watkins JT, Collins JF, Pilkonis PA, Beckham E, Glass DR, Dolan RT, Parloff MB (1992). Course of depressive symptoms over follow-up: findings from the National Institute of Mental Health Treatment of Depression Collaborative Research Program. Archives of General Psychiatry 49, 782-787.

Turner EH, Matthews AM, Linardatos E, Tell RA, Rosenthall R (2008). Selective publication of antidepressant trials and its influence on apparent efficacy. New England Journal of Medicine 358, 252-260.

Whitaker R (2010). Anatomy of an Epidemic: Magic Bullets, Psychiatric Drugs, and the Astonishing Rise of Mental Illness in America. Crown Publishers: New York. 